\title{
A Review of Interpreting Teaching Research in China Based on CiteSpace (2008-2018)
}

\author{
Chen Liu ${ }^{1} \&$ Jinjin Zhang ${ }^{1}$ \\ ${ }^{1}$ English Department, School of Foreign Languages, Neusoft University of Information, Dalian, China \\ Correspondence: Chen Liu, English Department, School of Foreign Languages, Neusoft University of \\ Information, Dalian, China.
}

Received: October 10, 2018 Accepted: December 10, 2018 Online Published: December 12, 2018

doi: 10.5539/elt.v12n1p85 URL: https://doi.org/10.5539/elt.v12n1p85

\begin{abstract}
After thirty years of development, the teaching of interpreting in China has achieved a moderate scale giving the credit to the growing demand for interpreting talents, as well as the spread of interpreting teaching among universities. This study reviewed the papers on interpreting teaching research published for the past decade in China covered by Chinese Social Sciences Citation Index (CSSCI) of foreign languages and education studies, explored the quantity of publications, source journals, authors, institutions and research hotspots by CiteSpace, depicted the mapping knowledge domain and analyzed the problems of the current research. Through bibliometric analysis, it is found that (1) High-level interpreting teaching research papers are produced in limited quantities; (2) Interpreting teaching research in China has not yet formed an independent research field; (3) The traits of interpreting discipline are not obvious enough; (4) The cross-sectional research and the longitudinal study have not been widely concerned; (5) The research on the backwash effect of interpreting tests are few; (6) The research on interpreting teaching at universities of applied sciences are limited. Based on the research findings, reference for further study of interpreting teaching would be provided.
\end{abstract}

Keywords: interpreting teaching research, CiteSpace, bibliometric analysis

\section{Introduction}

Interpreting teaching research began with the establishment of United Nations Interpreter Training Course at Beijing Foreign Studies University in the late 1970s. Later, in the mid-1990s, Beijing Foreign Studies University established the Graduate Institute of Interpretation and Translation (GIIT). Soon after that, in 2000, English interpreting became a compulsory course for senior English majors in the newly revised Syllabus for English Bachelor of Arts Program. In 2004, Shanghai International Studies University established the GIIT, followed by Guangdong University of Foreign Studies the next year. In 2006, Ministry of Education of the People's Republic of China approved the establishment of the Bachelor of Translation and Interpreting (BTI), and in 2008, the Master of Translation and Interpreting (MTI) was established with approval by the Department of Degree Management \& Postgraduate Education (Office of the State Council Academic Degrees Committee). As of February 2018, 399 universities in China are qualified to provide BTI and MTI education ( 99 of them provide both BTI and MTI education), of which interpreting courses are included at most universities. Interpreting teaching flourished within universities of China, and certain research, which proved to be great contributions to the development of interpreting teaching, were conducted for the past decades.

This study carried out a bibliometric analysis of papers on the research of interpreting teaching in China in the past decade (2008-2018), and depicted the mapping knowledge domain, aiming at making an overview of the development of interpreting teaching research in China and promoting the development of interpreting discipline.

\section{Research Design}

The purpose of this study is to analyze the problems of current research on interpreting teaching in China by the review of quantity of publications, source journals, authors, institutions and research hotspots for the past decade. The study selected the papers covered by Chinese Social Sciences Citation Index (CSSCI) of foreign languages and education studies in the China National Knowledge Internet (CNKI) database, retrieved the keyword of "interpreting teaching", described statistics and discussed the problems through literature research method, 
bibliometric analysis method and CiteSpace software (a citation visualization analysis software, which can be used to demonstrate the structure, regularity and distribution, and can be applied to explore research hotspots, frontiers and trends when conducting scientific knowledge analysis).

\section{Review and Discussion}

The research findings of interpreting teaching in China for the past decade mainly include the following two parts.

\subsection{Review of Quantity of Publications, Source Journals, Authors, Institutions and Research Hotspots}

High-level interpreting teaching research papers (covered by Chinese Social Sciences Citation Index (CSSCI) of foreign languages and education studies) are produced in limited quantities, with 269 papers published in the past decade (2008-2018): an average of fewer than 25 papers per year with a peak (34) in 2011 giving the credit to the establishment of BTI (in 2006) and MTI (in 2008) in China, as is shown in Figure 1.

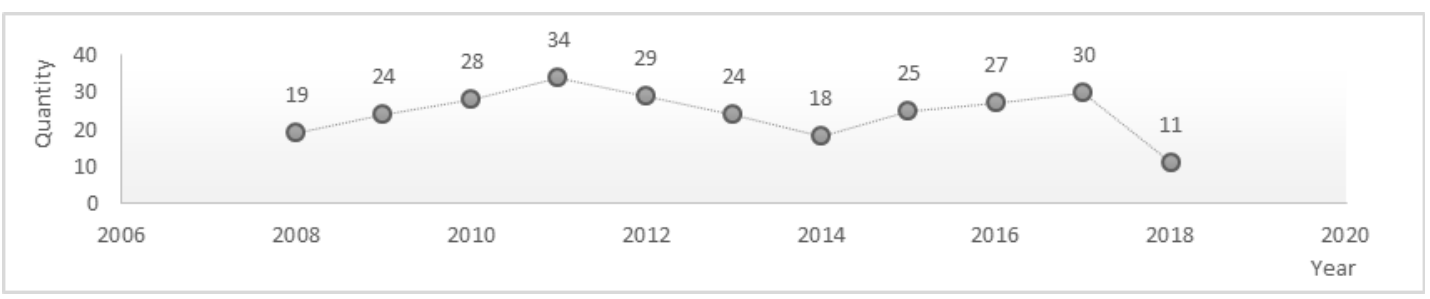

Figure 1. The number of papers covered by CSSCI index for the past decade

Of the journals where the research on interpreting teaching were covered, Chinese Translators Journal, accounting for $36.43 \%$, published the most (98) in comparison with the very few publications in journals of education studies, with less than 10 papers covered in Journal of the Chinese Society of Education and Higher Education Exploration as is shown in Table 1 and Table 2, reflecting interpreting teaching research in China still leech on to the foreign languages teaching research, which has not yet formed an independent research field.

Table 1. The number of papers covered by CSSCI index of foreign languages studies

\begin{tabular}{ll}
\hline Journal & Quantity \\
\hline Chinese Translators Journal & 98 \\
Computer-assisted Foreign Language Education & 36 \\
Foreign Language World & 33 \\
Foreign languages and Their Teaching & 18 \\
Journal of Foreign Languages & 14 \\
Foreign language Education & 14 \\
Foreign Language Teaching and Research & 10 \\
Modern Foreign Languages & 4 \\
Foreign Language Learning Theory and Practice & 4 \\
\hline
\end{tabular}

Table 2. The number of papers covered by CSSCI index of education studies

\begin{tabular}{ll}
\hline Journal & Quantity \\
\hline Journal of The Chinese Society of Education & 4 \\
Higher Education Exploration & 2 \\
\hline
\end{tabular}

In terms of journal authors and institutions, Zhang Wei, from Beijing Foreign Studies University, published the most (13 papers), followed by Wang Binhua (11 papers) of the University of Leeds. Guangdong University of 
Foreign Studies is second to none in the contribution of interpreting teaching research in China, with 30 papers being covered, followed by Beijing Language and Culture University (15 articles), Shanghai University of Foreign Studies (12 articles) and Hong Kong Polytechnic University (5 articles), reflecting universities of foreign studies are still the main source of prestigious journals of interpreting teaching research. As a senior college for interpreting research, Guangdong University of Foreign Studies is second to none in the contribution of interpreting teaching research in China.

The keywords with high frequency retrieved by CiteSpace reflect the research hotspots of interpreting teaching for the past decade as is shown in Figure 2: the larger the nodes present in the map, the higher the frequency of keywords will be. It is clearly seen that the largest node in the map is "interpreting teaching", followed by "interpreting" and "interpreting research", as were retrieved for 37 times, 28 times and 26 times respectively; Besides, "simultaneous interpreting" and "consecutive interpreting" were proved to be the hotspots for the past decade with more than 10 times retrieve as well.

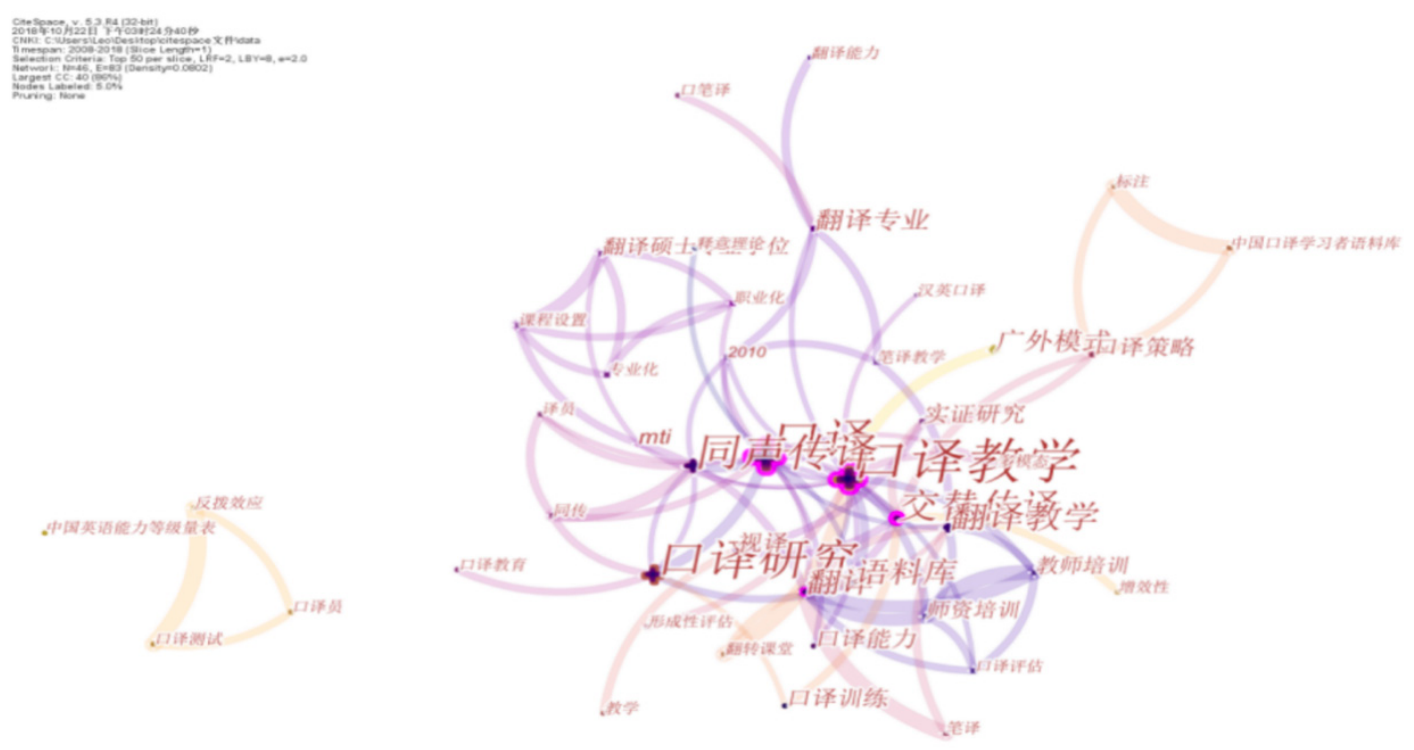

Figure 2. Keyword clustering map

\subsection{Discussion}

Traits of research on interpreting teaching were less distinct with leeching on to the research framework of translation teaching, which can be seen from the retrieved keywords with high frequency of "translation" (8 times) and "translation teaching" (9 times) in Table 3; at the same time, "simultaneous interpreting", "consecutive interpreting", "sight interpreting" and "interpreting strategy" show low frequency, which indicates that the cross-sectional research on simultaneous interpreting, consecutive interpreting and sight interpreting have not received sufficient attention, and the longitudinal study of interpreting techniques has not been widely concerned.

Zhong (2016) introduced the features of “广外模式” (defined as “interpreting teaching mode of Guangdong University of Foreign Studies") systematically from the aspects of skill training, theory instruction and teaching quality evaluation supported by research achievements, guided by systematic teaching concepts, and supplemented by sets of teaching materials. “厦大模式” (defined as “interpreting teaching mode of Xiamen University"), correspondingly, emphasizes that interpreting teaching should focus on skill training with the aid of language training, knowledge acquisition, and intercultural communication skills. (Zhong, 2001; Chen \& Xiao, 2014) These two modes have played an invaluable role in the construction of the interpreting teaching system, and have been promoting the research and development of interpreting teaching in China.

Wang (2010) has pointed out that the lack of studies on the backwash effect of translation test are incompatible with the flourish of translation disciplines and translation tests. The research on the backwash effect of test is also scarce in the field of interpreting teaching, as is shown in the Table 3 with the retrieved keywords of "interpreting evaluation" ( 2 times) and "interpreting test" ( 2 times). 
Corpus research proves to be an inevitable trend of informatization in the development of interpreting teaching as is shown in the Table 3 with the retrieved keywords of "corpus" (7 times). Guo (2018) proposed that interpreting teaching based on ICT technology has enjoyed unprecedented attention in the era of highly developing information and network techniques, interpreting teaching research, affected by new teaching methods and teaching modes such as MOOC and flipped classes, focus more on the construction of interpreting corpus resources.

Table 3. Frequency and centrality of keywords

\begin{tabular}{llll}
\hline Keyword & F & Keyword & $\mathrm{C}$ \\
\hline Interpreting Teaching & 37 & Interpreting & 0.54 \\
Interpreting & 28 & Interpreting Teaching & 0.52 \\
Interpreting Research & 26 & Consecutive Interpreting & 0.51 \\
Simultaneous Interpreting & 18 & Translation & 0.24 \\
Consecutive Interpreting & 12 & Translation major & 0.16 \\
Translation Teaching & 9 & Interpreting strategy & 0.15 \\
Translation & 8 & Simultaneous Interpreting & 0.13 \\
Corpus & 7 & Professionalization & 0.11 \\
Guangwai Mode & 6 & Interpreting Research & 0.10 \\
Translation Major & 5 & MTI & 0.10 \\
Sight Interpreting & 4 & Sight Interpreting & 0.08 \\
Interpreting Strategy & 4 & Translation Teaching & 0.05 \\
Interpreting Evaluation & 2 & Interpreting Evaluation & 0.00 \\
Interpreting Test & 2 & Interpreting Test & 0.00 \\
\hline
\end{tabular}

Notes: F referring to Frequency; $\mathrm{C}$ referring to Centrality.

"Professionalization" and "MTI" show strong centrality, which mainly benefits from globalization and information technology innovation in China, so that the translation, as a profession, develops rapidly. At the same time, since the Office of the State Council Academic Degrees Committee approved the establishment of the MTI in 2007, the interpreting teaching has been flourishing, which makes a considerable number of scholars devote themselves into the study of interpreting teaching.

Since most members within the Association of Universities (Colleges) of Applied Sciences (established in 2013) have transformed from vocational school to university of applied sciences, few scholars in China shifted to conduct the research on interpreting teaching at university of applied sciences, and the lack of experience from other countries and research results from major scholars makes it difficult for implementers to use mature experience as reference. Liu (2017) Limited research can be summarized into the following major categories: interpreting teaching reform, mode of interpreting talent cultivation, interpreting curriculum development, interpreting practice teaching and project-based interpreting teaching.

\section{Conclusion}

For the past decade, universities of foreign studies in China, represented by Guangdong University of Foreign Studies, have made great contributions to the research on interpreting teaching in China. The overall research is marked by features of a given era. Although the theoretical research hotspots tend to be diversified, high-level interpreting teaching research papers are produced in limited quantities with the traits of interpreting discipline being not obvious enough. Interpreting teaching research in China still leech on to the foreign languages teaching research, which has not yet formed an independent research field, and the cross-sectional research and the longitudinal study have not been widely concerned. Besides, the research on the backwash effect of interpreting tests are few, and the research on interpreting teaching at universities of applied sciences are limited. Interpreting teaching research needs to attach great importance to the traits of interpreting discipline and closely keep abreast of the times so as to demonstrate its own research features and better apply into interpreting teaching practice. 


\section{References}

Chen, J., \& Xiao, X. Y. (2014). Interpreting Teaching: From Theory to Classroom. Shanghai: Shanghai Foreign Language Education Press. https://doi.org/10.1075/intp.16.1.07che

Guo, L. J. (2018). A Summary of China's Interpretation Teaching Research Development in the Era of Highly Developing Information and Network Techniques: Based on the Analysis of Prestigious Journals in the Past Five Years. Foreign Language Education and Translation Development Innovation Research, 7, 214.

Liu, W. H. (2017). Research on Curriculum Mode of Undergraduate Education of Applied Sciences (pp. 26-27). East China Normal University.

Wang, K. F., \& Yang, Z. L. (2010). Theoretical and Practical Issues in Translation Tests. Foreign Languages.

Zhong, W. H. (2001). Interpreting training: Mode, Content, Method. Chinese Translators Journal, 30-33.

Zhong, W. H., \& Zhan, C. (2016). The Construction of Interpreting Teaching System: Theory and Practice for the System of Interpreting Teaching in Guangdong University of Foreign Studies I. Chinese Translators Journal, 39-42.

\section{Copyrights}

Copyright for this article is retained by the author(s), with first publication rights granted to the journal.

This is an open-access article distributed under the terms and conditions of the Creative Commons Attribution license (http://creativecommons.org/licenses/by/4.0/). 